\title{
Análisis de 1.000 casos de estudios metabólicos en Chile con PET ${ }^{18}$ Flúor-deoxiglucosa (FD G)
}

\author{
Teresa Massardo ${ }^{1,2,3}$, M. Josefina Jofré2, \\ Paulina Sierralta², José Canessa2,3,4, \\ Patricio González ${ }^{1,2,3}$, Pamela Humeres ${ }^{2,5}$, \\ Robert Valdebenito ${ }^{2 a}$.
}

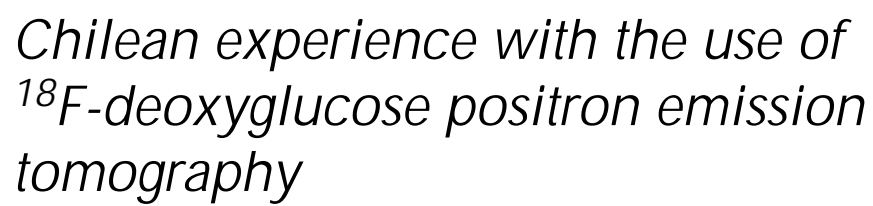

Background: Clinical oncology is the main application of ${ }^{18} \mathrm{~F}$ deoxyglucose (FDG) positron emission tomography (PET). Aim: To evaluate the first 1,000 patients studied with FDG PET in Chile. Material and methods: Retrospective analysis of 1,000 patients (aged between 1 and 94 years, 550 females) studied with FDG PET, since 2003. All studies were performed in a high resolution Siemens Ecat-Exact HR (+). All reports were based on the visual analysis of three plane and three-dimensional images. Results: Ninety seven percent of exams were done for oncological indications, mainly lung lesions, lymphoma, colorectal and gastroesophageal, cancer and breast tumors. Only $1 \%$ of patients had brain tumors. Non tumor neurological indications corresponded to $1.7 \%$. Cardiac studies were only $0.3 \%$ and inflammatory process corresponded to $1 \%$. The $5.6 \%$ corresponded to pediatric population. Six percent of patients were aged less than 18 years and in $50 \%$ of them, the indication was oncological, mainly lymphomas, brain tumors, endocrine cancers and sarcomas. The remaining $50 \%$ had a neurological indications, mainly for refractory epilepsy. Conclusions: PET FDG imaging was effective in the management of diverse diseases of children and adults (Rev Méd Chile 2007; 135: 375-83).

(Key words: Oncology, radiation; Positron-emission tomography; Tomography, emission-computed)

Recibido el 6 de abril, 2006. Aceptado el 3 de julio, 2006.

${ }^{1}$ Sección Medicina Nuclear, Departamento de Medicina, Hospital Clínico Universidad de Chile. ${ }^{2}$ Centro PET de Imágenes Moleculares, Hospital Militar de Santiago. ${ }^{3}$ Centro Radiológico Fleming. ${ }^{4}$ Medicina Nuclear Hospital Dipreca. ${ }^{5}$ Medicina Nuclear, Clínica Santa María.

aTecnólogo Médico

\footnotetext{
Correspondencia a: Dra. Teresa Massardo. Sección Medicina Nuclear, Departamento de Medicina, Hospital Clínico Universidad de Chile. Santos Dumont 999-1E, Independencia, Santiago, Chile. Fono: 7770569. Fax: 7777618. E mail: tmassardo@redclinicauchile.cl; centropet@hosmil.cl
} 
L a principal aplicación de las imágenes metabódicas con tomografía de positrones (PET) es oncológica. La mayoría de los tumores invasivos 0 de alto grado tienen avidez por la ${ }^{18} \mathrm{~F}$-deoxiglucosa (FDG). Su uso está demostrado para caracterizar lesiones pulmonares, en tumores de esófago, mama, linfomas, colorrectales, cabeza y cuello, melanoma y tiroides. Los renales, ginecológicos y de origen desconocido son otras indicaciones. Los poco agresivos no son adecuados para evaluación con FDG (prostático, linfomas de bajo grado o testiculares diferenciados). En general, en tumores metabólicamente activos la sensibilidad y especificidad es alrededor o sobre 90\%. Los falsos negativos se asocian a lesiones bajo la resolución del equipo, a tumores de bajo grado o mucinosos; los falsos positivos, a proceso inflamatorio activo, por lo que deben considerarse cuidadosamente todos los antecedentes: quimioterapia o radioterapia recientes, cirugías y cuadros infecciosos ${ }^{1-7}$.

El PET-FDG tiene un claro papel demostrado en la etapificación, reetapificación, evaluación de actividad tumoral en masa residual y control precoz o al término de terapia, además del valor pronóstico. Con equipos híbridos PET-Tomografía Computada (TC) es posible localizar mejor las alteraciones y definir campos de radioterapia.

Aunque la mayor experiencia ha sido en población adulta, la FDG tiene utilidad en tumores pediátricos prevalentes: sistema nervioso central, linfomas y sarcomas ${ }^{1,2,8-10}$.

El objetivo fue analizar el grupo inicial de pacientes estudiados con FDG en nuestro país, enfatizando indicaciones en adultos y pediátricas.

\section{MATERIAL Y MÉTODO}

Población. Se analizaron, retrospectivamente, los primeros 1.000 casos consecutivos desde el año 2003 incluyendo todas las solicitudes de diversos especialistas, principalmente, oncólogos y cirujanos de clínicas y centros hospitalarios chilenos, con 5\% latinoamericanos. La edad del grupo varió entre 1 y 94 años; 94,4\% correspondió a mayores de 18 años con 55\% de sexo femenino. La glicemia en ayunas preinyección de FDG fue $<160 \mathrm{mg} / \mathrm{dl}$ en $99 \%$ de los casos. El 7\% era diabético, la mayoría tipo II, en control. Se requirió insulina cristalina en 24\% (glicemia preinyección: $111 \pm 26 \mathrm{mg} / \mathrm{dl}$ ). En los pacientes cardiológicos se indicó colación $(150 \mathrm{~g}$ de hidratos de carbono) y acipimox.

Radiofármaco. FDG producto de ciclotrón IBA Cyclone 18/9 (Comisión Chilena de Energía Nuclear). Dosis promedio: $13 \pm 3 \mathrm{mCi}$; en niños, promedio: $8 \pm 4 \mathrm{mCi}$ (rango: $1-15 \mathrm{mCi}$ ).

Equipo y adquisición. PET dedicado de alta resolución Siemens Ecat-Exact $\mathrm{HR}(+)$; imágenes con múltiples campos de emisión y transmisión de cuerpo entero desde cráneo a tercio proximal de muslos y segmentarias complementarias, según necesidad.

Interpretación. Informes consensuados basados en análisis visual de imágenes en 3 planos y tridimensionales. La cuantificación SUV (Standardized Uptake Value) se usó para seguimiento. Se realizaron imágenes fusionadas con TC o resonancia magnética disponibles, que permitió mejor correlación anatómica, especialmente, en tórax.

Análisis. Se determinaron las características de la población y sus indicaciones, algunos detalles técnicos, resultados histológicos, seguimiento $\mathrm{y}$ cambios de conducta, en los subgrupos en que estuvieron disponibles.

\section{RESULTADOS}

A. Generales. En sólo 1,1\% de los casos se requirió sedación o anestesia: en síndromes convulsivos pediátricos o en claustrofobia. Se debió repetir el examen en 2 diabéticos mal controlados, a pesar de uso de insulina, por captación muscular elevada y en 1 caso por presencia de grasa parda. El $16 \%$ de los estudios correspondió a seguimiento en patología colorrectal (21\%), linfomas (18\%) y cáncer pulmonar (16\%). Se confirmaron histológicamente 7 segundos tumores primarios no conocidos, 5 de ellos malignos (Figura 1).

En los pacientes oncológicos, la FDG fue positiva en $59 \%$ para tumor maligno; se planteó efectuar correlación con imágenes anatómicas 0 histología en $8 \%$ de todos los informes.

B. Experiencia de imágenes con PET-FDG en adultos. Las principales indicaciones están descritas en Tabla 1. Los pacientes oncológicos corres- 


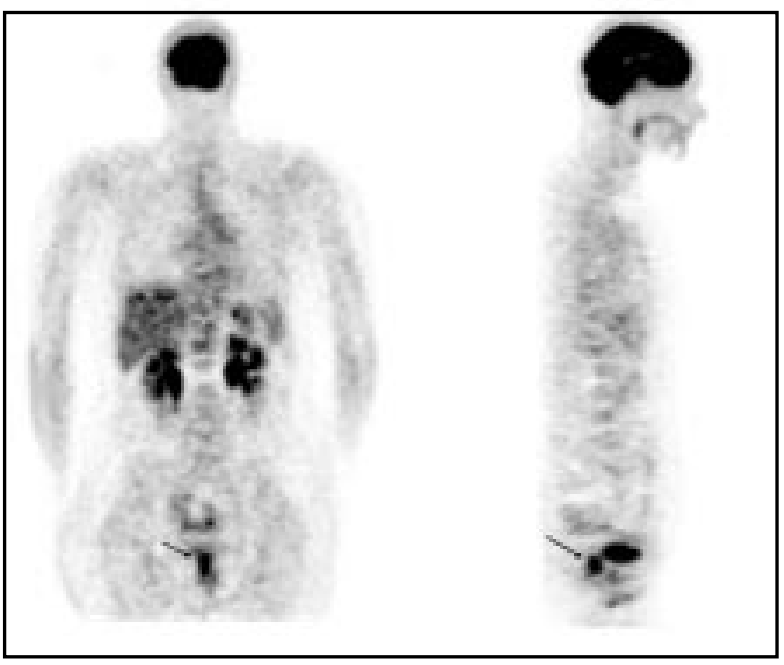

Figura 1. Paciente de sexo femenino de 60 años con antecedente de cáncer cervicouterino y melanoma. Se desea reetapificación. PET FDG: foco hipermetabólico rectal (flecha, en imágenes coronal y sagital). La histología confirma adenocarcinoma, que corresponde a hallazgo de tumor primario rectal.

pondieron a 97\%. En tumores cerebrales, la solicitud fue evaluación de recidiva $y$, en la neurológica no tumoral $(1,7 \%)$ para trastornos del ánimo, cognitivos o epilepsia. La solicitud cardiológica, para confirmar viabilidad miocárdica por eventual revascularización coronaria fue $0,3 \%$.
Además, hubo exámenes por screening de cáncer y síndromes paraneoplásicos. En 2 casos con fiebre prolongada de origen desconocido se encontró hipermetabolismo ganglionar hiliar y mediastínico, con histología de tipo granulomatoso, compatible con sarcoidosis (Figura 2).

Tabla 1. C ausa de solicitud de PET FD G en patología de adultos

\begin{tabular}{|c|c|c|c|c|}
\hline Solicitud & Patología & $\mathrm{n}$ & Subtotal (\%) & Total (\%) \\
\hline Oncológica & $\begin{array}{l}\text { Cáncer pulmonares y NPS } \\
\text { Cáncer colorrectal } \\
\text { Gastroesofágico } \\
\text { Otros digestivos } \\
\text { Hepatoma } \\
\text { Hematológicos } \\
\text { Genito-urinarios } \\
\text { Melanomas } \\
\text { Mamaria } \\
\text { Tiroideos/Neuroendocrinos } \\
\text { Primarios desconocidos } \\
\text { Sarcomas } \\
\text { Tumores cabeza y cuello } \\
\text { Otros tumores } \\
\text { Tumores cerebrales } \\
\text { Screening tumoral } \\
\text { S. paraneoplásicos }\end{array}$ & $\begin{array}{r}201 \\
96 \\
26 \\
31 \\
3 \\
115 \\
109 \\
81 \\
63 \\
58 \\
38 \\
33 \\
26 \\
14 \\
9 \\
5 \\
5\end{array}$ & $\begin{array}{c}17 \\
13 \\
12 \\
9 \\
7 \\
6 \\
4 \\
3 \\
3 \\
2 \\
1 \\
1\end{array}$ & 97 \\
\hline Neurológica & Demencia, epilepsia y trastornos ánimo & 16 & & 1,7 \\
\hline Cardiológica & Viabilidad miocárdica & 3 & & 0,3 \\
\hline $\begin{array}{l}\text { Otras causas } \\
\text { Total }\end{array}$ & $\begin{array}{l}\text { Tumores benignos } \\
\text { Inflamaciones y fiebre }\end{array}$ & $\begin{array}{r}6 \\
4 \\
944\end{array}$ & & $\begin{array}{r}1 \\
100\end{array}$ \\
\hline
\end{tabular}




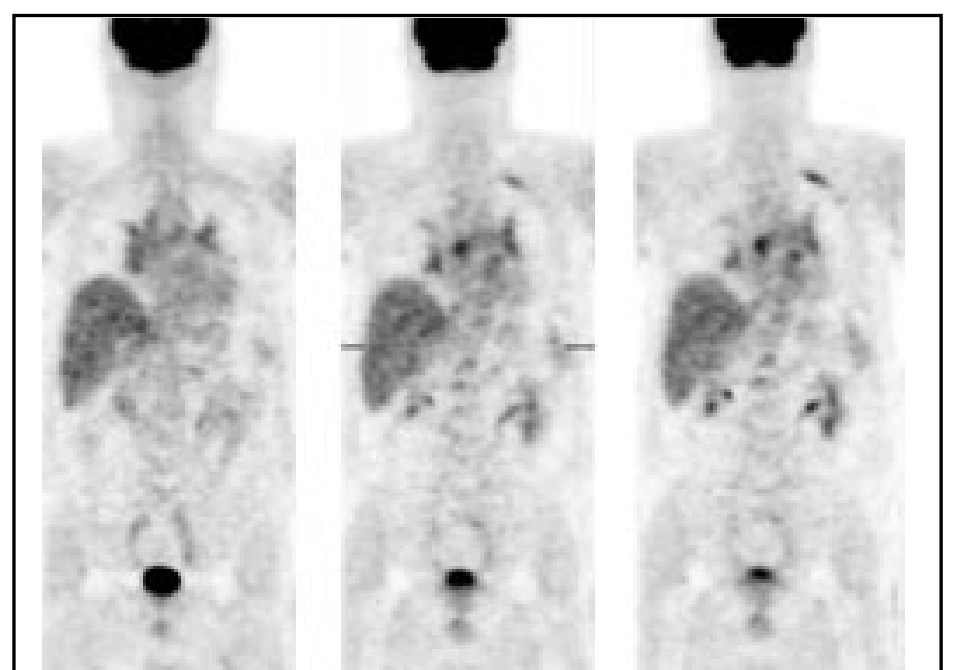

Figura 2. Hombre de 65 años, en evaluación por nódulos pulmonares bilaterales, mediastínicos e hiliares encontrados en TC, se requería descartar sarcoidosis versus proceso neoplásico. PET FDG: múltiples focos de moderada intensidad con aspecto de linfonodos en mediastino, hilios pulmonares, pleurocostal, supraclavicular izquierdo y lumboaórticos que sugieren compromiso inflamatorio como primera posibilidad. Punción biopsia bajo TC: alteración linfática tipo sarcoidosis.

- Lesiones pulmonares: Fue la principal indicación en adultos con $22 \%$ : evaluación de cáncer pulmonar conocido en $63 \%$ y nódulos pulmonares solitarios (NPS) en 37\%. El seguimiento se obtuvo en 47 pacientes; $80 \%$ de 35 estudiados por sospecha de recidiva o reetapificación de cáncer conocido tuvo FDG positivo, los que recibieron nuevos tratamientos. En 4 casos, sometidos a cirugía posterior, se confirmó resultado del PET. En $49 \%$ de 39 pacientes, con NPS o masa pulmonar, que tenían FDG negativo, la conducta ha sido seguimiento con TC. En pacientes con FDG positivo, la histología confirmó el resultado del PET en 88\%: con sólo 2 falsos positivos: un schwannoma abscedado y un gran hamartoma. Un paciente con cáncer gástrico y nódulos pulmonares de hasta $8 \mathrm{~mm}$ no demostró captación anormal; sin embargo, la histología fue positiva para metástasis.

- Tumores digestivos y hepáticos: Correspondieron a $17 \%$ de los pacientes oncológicos adultos: $44 \%$ cáncer colónico, $17 \%$ rectal, $10 \%$ gástrico, $8 \%$ pancreático, $6 \%$ esofágico y $15 \%$ restante a otros tipos, que incluían de vía biliar y estromales (GIST). El 74\% de los estudios fue positivo con FDG.

En cáncer colorrectal, 57\% fue enviado por sospecha de recidiva, elevación de CEA con imágenes anatómicas negativas. En 75\% se encontraron focos hipermetabólicos tumorales. En 31\%, la indicación fue reetapificación; $68 \%$ fueron positivos, $60 \%$ en hígado, con lesiones confirmadas; la mayoría inició nuevos esquemas de quimioterapia.

En páncreas, 38\% fue referido para caracterización de lesión; se confirmó actividad maligna en 4/6. Asimismo, 44\% fue referido por sospecha de recidiva en imágenes o elevación de CA 19-9, observándose $85 \%$ con hipermetabolismo, especialmente hepático y abdominal, confirmados en $57 \%$.

En estómago y esófago fueron positivos para tumor en $85 \%$ y $89 \%$, respectivamente. Las indicaciones fueron etapificación, reetapificación, sospecha de recurrencia y control terapéutico.

En los cánceres biliares referidos por sospecha de recidiva, $67 \%$ mostró nuevos focos de actividad maligna. En hepatocarcinomas, referidos por sospecha de recidiva y elevación de alfa-fetoproteínas, hubo nuevos focos en $75 \%$. Los 9 tumores GIST estudiados correspondieron a 8 casos operados; 6/9 para evaluar terapia con Imatinib y el resto para reetapificación y eventual uso de éste: $67 \%$ fueron positivos (Figura 3).

- Patología hematológica: Correspondió a 13\% de las indicaciones oncológicas en adultos. Los linfo- 
mas fueron $96 \%$ y el resto plasmocitoma solitario y leucemia crónica. En los linfomas, 37\% fue de tipo Hodgkin. Las indicaciones fueron etapificación (19\%), reetapificación incluyendo evaluación pretrasplante de médula ósea (36\%), evaluación de masa residual (12\%) y control de terapia (34\%). El 68\% de los estudios fueron positivos para actividad tumoral maligna. En control de terapia, $55 \%$ fue positivo, lo que apoyó continuar o modificar esquemas. Los con seguimiento en $85 \%$ fueron linfoma no Hodgkin (LNH), para reetapificación, control de masa residual y evaluación terapéutica. Varios LNH, a pesar de ser de bajo grado, mostraron focos hipermetabólicos; 5/7 linfomas foliculares fueron positivos multifocales y uno negativo con FDG anormal previo correspondió a buena respuesta terapéutica. En uno de los casos iniciales, se informó actividad a nivel tímico que correspondió histológicamente a hiperplasia.

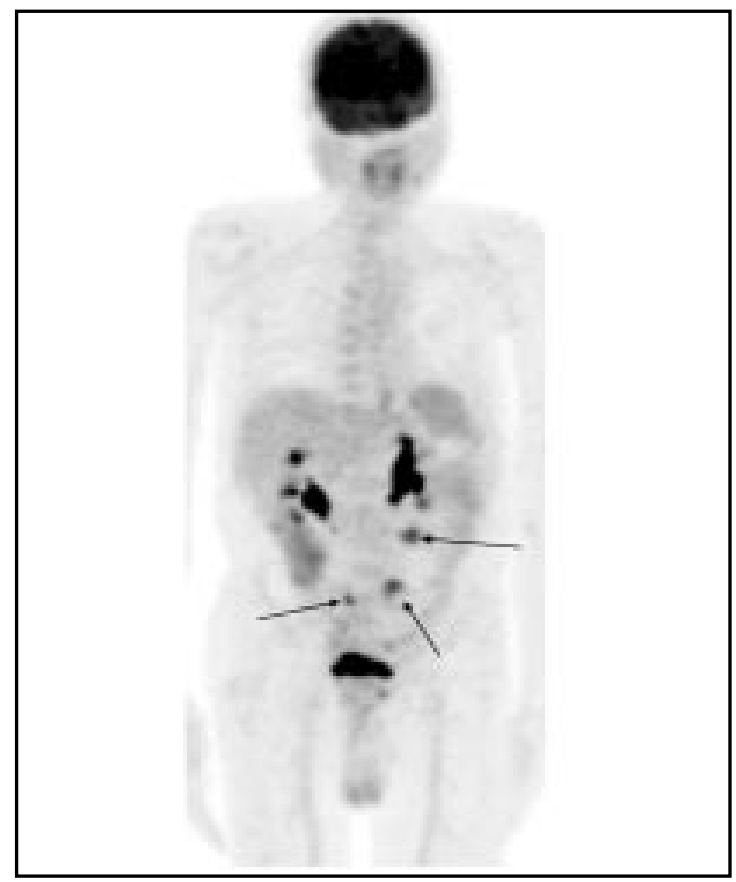

Figura 3. Paciente de sexo masculino de 72 años, con antecedente de GIST irresecable diagnosticado y tratado con Glivec ${ }^{\circledR}$ por 3 meses con respuesta $>50 \%$. Operado posteriormente con enfermedad peritoneal. Continúa con tratamiento; el FDG de control demuestra 3 focos compatibles con actividad metabólica en implantes peritoneales (flechas).
- Melanoma: Fue 9\% del total oncológico adulto enviados principalmente para reetapificación. El $39 \%$ tuvo FDG positivo para actividad maligna, 58\% con múltiples focos hipermetabólicos. En seguimiento de un subgrupo, se confirmó tumor histológicamente en 7/11 casos; en los restantes, hubo concordancia con clínica e imágenes anatómicas. El PET demostró lesiones no sospechadas por otros estudios (no confirmadas). Hubo 2 falsos positivos: hematoma organizado y adenopatía inflamatoria. Se estudiaron 4 pacientes con melanoma ocular, 3 negativos a pesar del tumor in situ y otro con lesiones hepáticas compatibles con hemangiomas en ecografía y RM, captantes con FDG, considerándose como diseminación.

- Cáncer de mama: Correspondió a 7\% del grupo oncológico adulto, todos de sexo femenino. Las indicaciones fueron: reetapificación (47\%), sospecha de recidiva (27\%), control de tratamiento (17\%), diagnóstico $(5 \%)$ y etapificación postcirugía mamaria (3\%). En reetapificación, 61\% tuvo FDG negativo con buena evolución con seguimiento de hasta 24 meses. El 63\% de los estudios positivos presentaron focos no sospechados; hubo buena comelación en lesiones conocidas. La mayonía continuó con quimioterapia u hormonoterapia. Las sospechas de recidiva fueron por: nódulos pulmonares (31\%), alteraciones mamográficas (25\%) o aumento del CA 15-3 (19\%). El FDG fue positivo en $56 \%$, con nuevas lesiones en $67 \%$ y recidivas locales en 33\%, confirmadas. Del grupo de control terapéutico, el FDG fue negativo en $10 \%$, las pacientes con regresión parcial o progresión, continuaron tratamiento. En $66 \%$ de las pacientes referidas para diagnóstico, se confirmó el foco primario.

- Tumores génito-urinarios: Correspondieron a $13 \%$ del total de tumores del adulto. De ellos, en conjunto: $28 \%$ ováricos, $31 \%$ cervicouterinos y sólo $3 \%$ de endometrio, $17 \%$ testiculares, $8 \%$ prostático, $8 \%$ renales, $6 \%$ vesicales y $2 \%$ restante a trompa de Falopio, vulvar, vaginal y uretral. Se obtuvo seguimiento en 32 pacientes con patología ovárica y uterina, 81\% con FDG positivo. En 96\%, existió buena correlación con imágenes, laboratorio, exploración quirúrgica o manejo clínico referente a presencia de neoplasia. De las con examen negativo, hubo correlación con la evolución en $83 \%$.

En tumores testiculares, sólo 11\% tuvo FDG positivo, a pesar de masas sugerentes de actividad, probablemente diferenciadas. En cambio, de los tumores prostáticos, 56\% tenían lesiones hiperme- 
tabólicas concordantes con otras imágenes respecto a diseminación ósea, linfática y pulmonar. En 2 casos se visualizó tumor prostático in situ.

Los tumores renales fuemon 8 casos, 2 recientemente operados, para etapificación, con FDG negativo, y los demás para reetapificación o control de terapia: 4 fueron positivos, 3 sospechosos de lesiones pulmonares y esqueléticas observadas con FDG y uno con lesiones no conocidas confirmadas (Figura 5).

- Tumores endocrinológicos: Correspondieron a 6\% del total oncológico adulto (excluyendo pancreáticos y gonadales). Los cánceres tiroideos diferenciados tratados fueron $81 \%$ : $71 \%$ papilares, $11 \%$ foliculares y $13 \%$ mixtos. La indicación del FDG fue la reetapificación por elevación de tiroglobulinas en $55 \%$, de anticuerpos anti-tiroglobulina en $8 \%$ o nodos cervicales u otras lesiones sospechosas en $32 \%$; la mitad de ellos con antecedentes de exploración sistémica con ${ }^{131}$ I negativa reciente; hubo 4 casos con ${ }^{131}$ I positivo (2 en lecho tiroideo). El 50\% de los estudios con FDG fue positivo en cáncer tiroideo diferenciado, 3 tenían exploración sistémica positiva. En los cánceres medulares tratados (19\% de los tiroideos) la indicación fue reetapificación (calcitonina elevada o sospecha de lesión cervical u ósea); el FDG fue positivo en $67 \%$.

Entre los tumores neuroendocrinos, 57\% carcinoides, el FDG fue positivo en $57 \%$ de ellos. En un carcinoma paratiroideo, hallazgo poscirugía de nódulo tiroideo con PTH elevada, el FDG fue negativo, concordante con imágenes anatómicas y estudio con 99mTc-sestamibi; se completó cirugía oncológica, con buena evolución.

C. Experiencia con PET-FDG en patología pediátrica. La población pediátrica correspondió sólo a $6 \%$ de la población total y la patología oncológica fue $50 \%$ (Tabla 2). El grupo de linfomas fue el mayor, con $29 \%$ del total oncológico, 6/8 LNH estudiados para reetapificación y control. El $75 \%$ de los linfomas tuvo FDG negativo, con buena evolución. En los 2 casos con FDG positivo, se cambió esquema de quimioterapia (Figuras 4a y 4b).

El 18\% fue cáncer tiroideo, al igual, que en adultos, la mayoría presentaba tiroglobulina elevada y exploración sistémica negativa. El FDG mostró focos cervicales en 3 de 5 casos, uno confirmado histológicamente.

Los sarcomas de partes blandas fueron estudiados para reetapificación, al igual que los tumores neuroendocrinos (neuroblastomas y ganglioneuroma). Se estudiaron para etapificación dos melanomas y un sarcoma de Ewing, que resultaron negativos y con buena evolución posterior.

Casos interesantes correspondieron a un carcinoma de parótida con histología de adenoma

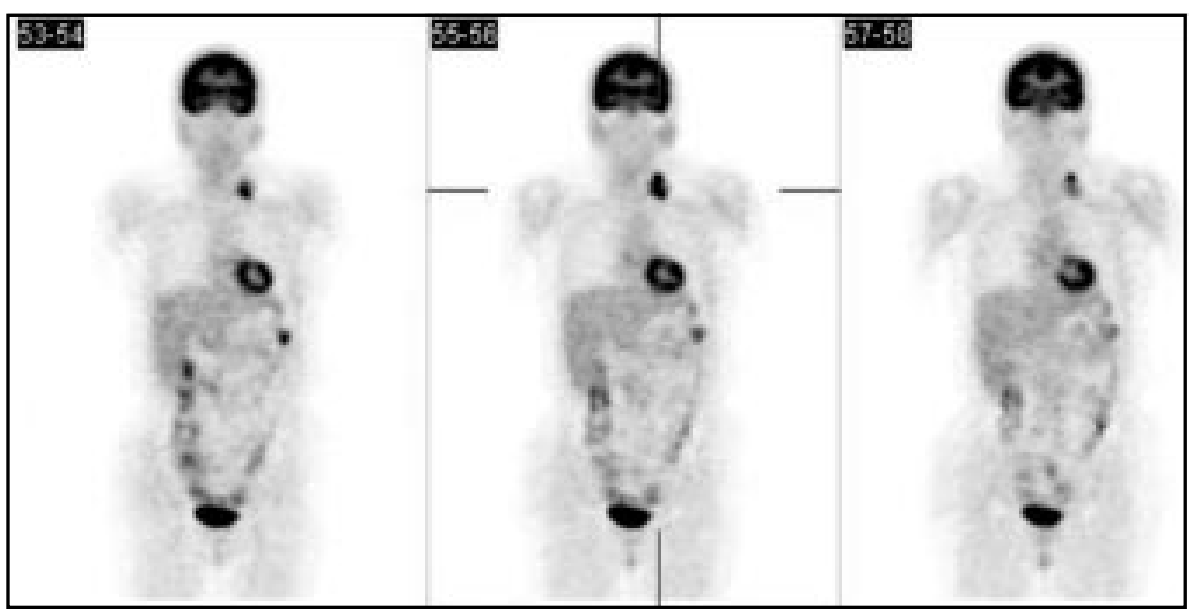

Figura 5. Mujer de 48 años con cáncer renal izquierdo (carcinoma transicional invasor de pelvis renal, con compromiso linfonodos hiliares y grasa perinodal). Operada y tratada con quimio y radioterapia. Doce meses posterapia, TC tórax, abdomen y pelvis sin recidiva tumoral. Se reetapifica con FDG al año siguiente: actividad hipermetabólica tumoral en linfonodos supra e infraclaviculares izquierdos, sin otras alteraciones. Biopsia ganglionar supraclavicular. metástasis. En vaciamiento ganglionar de 12 linfonodos, se demostró metástasis de cáncer de células transicionales renales. Sometida a quimioterapia posterior. Seguimiento clínico y con PET negativos. 
pleomorfo, con FDG positivo que requirió cirugía cervical adicional; un tumor de Wilms y una neurofibromatosis, ambos con FDG positivo.

Los tumores de sistema nervioso central fueron $14 \%$ de los cánceres pediátricos, todos solicitados para evaluar viabilidad posradioterapia (3/4 casos positivos con FDG fallecieron).

La solicitud de tipo neurológico no tumoral correspondió a 50\%, para evaluación de epilepsia refractaria en $86 \%$ y por causa neuropsiquiátrica en $14 \%$.

\section{Discusión}

El rendimiento del PET-FDG es excelente, confirmado en las revisiones de Gambhir y cols. y Rohren y cols ${ }^{1,2}$, que incluyen cánceres inicial-

Tabla 2. C ausa de solicitud de PET FD G en patología pediátrica

\begin{tabular}{|llccc|}
\hline Solicitud & Patología & $\mathrm{n}$ & Subtotal (\%) & Total (\%) \\
\hline Oncológica & Linfomas & 8 & 29 & \\
& Tumores tiroideos & 5 & 18 & \\
& Tumores cerebrales & 4 & 14 & 50 \\
& Neuroendocrinos & 3 & 11 & \\
& Sarcomas & 3 & 11 & \\
& Melanoma & 2 & 7 & \\
& Otros tumores & 3 & 11 & 50 \\
Neurológica & Epilepsia refractaria & 24 & 86 & 100 \\
& Neuropsiquiátricas & 4 & 14 & \\
\hline
\end{tabular}

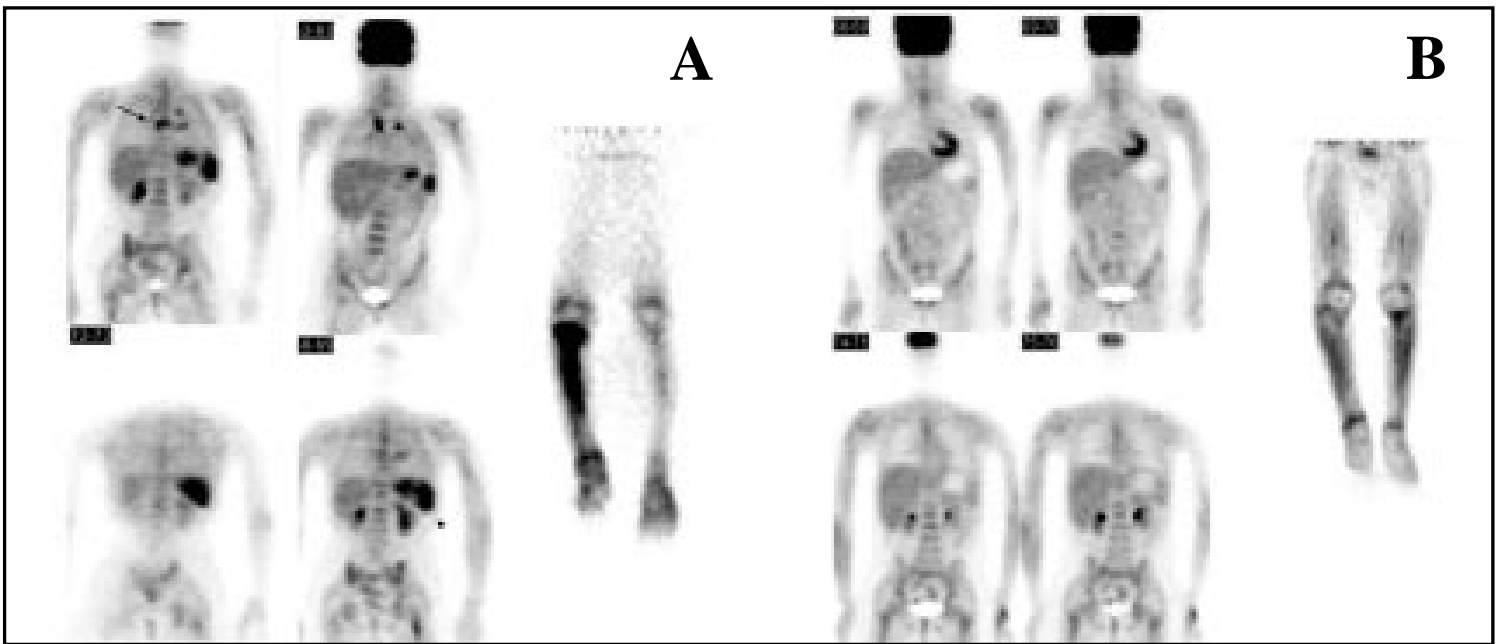

Figura 4a. Niña de 6 años, con linfoma linfoblástico de tibia derecha en quimioterapia de inducción. Las imágenes de FDG muestran compromiso supraclavicular, en hilios pulmonares y, múltiple, en esqueleto con intensa actividad tibial derecha (flecha) así como en bazo (cabeza de flecha).

Figura 4b. La misma paciente tuvo cambio de esquema de quimioterapia. Se efectúa control a los 3,5 meses, pretrasplante de médula ósea. Se observa mejoría significativa y sólo leve actividad residual en esqueleto, en extremidades inferiores, probablemente secundaria a terapia y trastornos de deambulación. 
mente aceptados por Medicare en Estados Unidos de Norteamérica (mama, melanoma, colorrectal, pulmón, linfoma, etc.). Esas indicaciones son también utilizadas en nuestro país ${ }^{11-14}$. En esta casuística se aprecia que, en adultos, los cánceres pulmonares y digestivos son preponderantes y, en niños, las indicaciones oncológicas y neurológicas tienen similar importancia por la mayor prevalencia de tumores cerebrales y epilepsia refractaria ${ }^{8,9}$.

En revisión de cáncer pulmonar ${ }^{15}$, se muestra que el PET-FDG es más seguro que las imágenes anatómicas convencionales en etapificación general y del mediastino en candidatos quirúrgicos, útil en planificación de radioterapia y que la etapificación predice con mayor seguridad la sobrevida de pacientes con radioterapia. La tasa de detección de metástasis no sospechadas fue sobre $20 \%$.

Debe mencionarse un metaanálisis en linfomas que demostró una mediana de sensibilidad de $90,3 \%$ y especificidad de $91,1 \%{ }^{16}$.

En detección de cáncer colorrectal recumente, el metaanálisis de Huebner y cols ${ }^{17}$, la sensibilidad global fue $97 \%$, con especificidad de $76 \%$. El cambio de manejo inducido por PET FDG ocumió en 29\%. En cáncer gástrico, el FDG tiene buena especificidad en evaluación nodal, incluso en casos avanzados ${ }^{18,19}$. Respecto a cáncer mamario, otro metaanálisis de Isasi y cols, mostró que el FDG-PET es útil para detectar recumencia y metástasis; la sensibilidad promedio fue $90 \%$ y con $11 \%$ de falsos positivos, mediana de sensibilidad $92,7 \%$ y de especificidad $81,6 \%{ }^{20}$.

La FDG también ayuda a evitar toxicidad innecesaria posterior a quimio o radioterapia a pacientes con sobrevida prolongada que puedan presentar otros procesos primarios posteriores,

\section{REFERENCIAS}

1. Gambhir SS, CZernin J, Schwimmer J, Silverman DH, Coleman RE, Pheips ME. A tabulated summary of the FDG PET literature. J Nucl Med 2001; 42: 1S-93S.

2. Rohren EM, Turkington TG, Coleman E. Clinical Applications of PET in Oncology. Radiology 2004; 231: 305-32.

3. González P, Massardo T, Canessa J, Humeres P, Jofré MJ. Aplicaciones clínicas del PET. Rev Méd Chile 2002; 130: 569-79.

4. Massardo T, Jofré MJ, Canessa J, González P, Humeres, $P$, SERRALTA P ET AL. Analysis of the initial experience limitando campos de radiación o con quimioterapia abreviada ${ }^{21}$, especialmente válido en linfomas de pacientes jóvenes, por los excelentes resultados terapéuticos y buen rendimiento de la técni$\mathrm{ca}^{22,23}$. Las dosis de irradiación a cuerpo entero en niños también pueden ser menores en seguimiento a largo plazo utilizándose imágenes metabólicas en vez de anatómicas, considerando que las dosis de FDG son bajas y la vida media corta ${ }^{10,24}$.

La buena relación costo beneficio obtenida con PET-FDG se mide no sólo en términos de sobrevida, sino también en menor requerimiento de exámenes anatómicos, cirugías o quimioradioterapias, con reducción de morbilidad asociada, optimizando el manejo de enfermedad ${ }^{24-26}$.

En esta casuística, no hubo dificultades en la adquisición ni procesamiento del PET-FDG, que no tiene contraindicaciones salvo embarazo sin interfenir con otros exámenes. Observamos que después de analizar los 250 casos iniciales ${ }^{4}$ existieron menos dificultades en la interpretación debido a mayor experiencia individual y grupal de los médicos, especialmente, con las variantes normales causadas por la excreción uninaria y captación intestinal.

En resumen, la FDG se ha utilizado en Chile para evaluación de diversas patologías, con franco predominio oncológico del adulto. Específicamente, en lesiones pulmonares, gastrointestinales y linfomas, se han observado cambios de conducta terapéutico. En niños, el control de linfomas fue la indicación más común. En concordancia con la literatura ${ }^{27-31}$, en cáncer tiroideo y neuroendocrino la utilidad es moderada, debiendo seleccionarse los pacientes; es menor en melanomas oculares, tumores testiculares diferenciados y para caracterizar lesiones $\varangle 6 \mathrm{~mm}$.

with first PET scanner and ${ }^{18} \mathrm{~F}$-FDG in Chile. Alasbimn Journal 7(29): July 2005. Article No AJ29-3.

5. Sierralta P, Jofré MJ, González P, Massardo T, Humeres P, CANESSA J. PET, tomografía por emisión de positrones: Presentación de un caso clínico. Rev Chil Radiol 2003: 9: 33-5.

6. Canessa J, Larach J, Massardo T, Jofré MJ, González P, Morales B et aL. Estudio de imágenes PET con Flúor ${ }^{18}$-Desoxiglucosa $\left(\mathrm{F}^{18} \mathrm{FDG}\right)$ en evaluación de elevación de marcador tumoral CA 19-9 en paciente con cistoadenocarcinoma mucinoso de páncreas. Rev Méd Chile 2004; 132: 347-52.

7. Massardo T, Canessa J, Jofré MJ, Humeres $P$, 
González P, SierRalta P. Utilidad de la tomografía de emisión de positrones (PET) con fluordeoxiglucosa (FDG) en patología oncológica. Rev Chil Cancerol Hematol 2003; 13: 9-28.

8. Jadvar H, Alavi A, Mavi A, Shulkin B. PET in pediatric diseases. Radiol Clin NAm 2005; 43: 135-52.

9. SHULKIN B. PET imaging in pediatric oncology. Pediatr Radiol 2004; 34: 199-204.

10. Jadvar H, Connoly LP, Shulkin BL. Pet imaging in pediatric disorders En: Positron emission tomography. Basic science and clinical practice. Eds: Valk P, Bailey D, Townsend D, Maisey M. Editorial Springer, London, 2003; 755-74.

11. Jofré MJ, Massardo T, González P, CANessa J, Sierralta P, Humeres P et al. Uso de la tomografía de emisión de positrones PET con $\mathrm{F}^{18}$-FDG en la evaluación de lesiones pulmonares. Rev Méd Chile 2005; 133: 583-92.

11. Jofré MJ, Sierralta P, Massardo T, Canessa J, GonzÁlez P, Humeres P et al. Valor de la tomografía de emisión de positrones con $\mathrm{F}^{18}$-fluordeoxiglucosa (PET-FDG) en pacientes con cáncer de mama. Rev Chil Cirugía 2005; 57: 384-8.

12. González P, Jofré J, Massardo T, Humeres P, Canessa J, SierRalta P. Uso de la tomografía de emisión de positrones en el cáncer colorrectal. Rev Chil Radiol 2002; 8: 72-9.

14. Massardo T, Canessa J, Jofré MJ, González P, Humeres P, SierRalta P. Utilidad de la deoxiglucosa marcada con flúor- ${ }^{18}$ (FDG) en el manejo de los linfomas. Rev Méd Chile 2006; 134: 910-9.

15. Mac Manus MP, Hicks RJ. PET scanning in lung cancer: current status and future directions. Semin Surg Oncol 2003; 21: 149-55.

16. IsAsI CR, Lu P, BLAufox MD. A metaanalysis of $18 \mathrm{~F}-$ 2-deoxy-2-fluoro-D-glucose positron emission tomography in the staging and restaging of patients with lymphoma. Cancer 2005; 104: 1066-74A.

17. HueBner RH, PARK KC, SHePHerd JE, SCHWimmerJ, CZERnIN J, PheIPS ME ET AL A meta-analysis of the literature for whole-body FDG PET detection of recument colorectal cancer. J Nucl Med 2000; 41: 1177-89.

18. Yun M, Lim JS, Noh SH, Hyung WJ, Cheong JH, Bong JK ET AL. Lymph node staging of gastric cancer using (18)F-FDG PET: a comparison study with CT. J Nucl Med 2005; 46: 1582-8.

19. KIm SK, Kang KW, Lef JS, KIm HK, Chang HJ, Choi JY ET AL. Assessment of lymph node metastases using (18)F-FDG PET in patients with advanced gastric cancer. Eur J Nucl Med Mol Imaging 2006; 33: 148-55.

20. ISASI CR, Moadel RM, BLaUfox MD. A meta-analysis of FDG-PET for the evaluation of breast cancer recurrence and metastases. Breast Cancer Res Treat 2005; 90: 105-12.

21. Ng AK, Bernardo MY, Weluer E, Backstrand K, Silver B, Marcus KC et aL. Second malignancy after Hodgkin disease treated with radiation therapy with or without chemotherapy: long-term risks and risk factors. Blood 2002; 100: 1989-96.

22. Jerusalem G, Rigo P. PET imaging in lymphoma. En: Positron emission tomography. Basic Science and clinical practice, Eds: Valk P, Bailey D, Townsend D, Maisey M. London: Editorial Springer, 2003; 547-58.

23. HicKs RJ. PET in lymphoma and malignant melanoma. En: Nuclear Medicine in clinical diagnosis and treatment. Eds.: Ell PJ, Gambhir SS. Editorial Churchill Livingstone, Edinburgh, 2004; 23-34.

24. Wegner EA, Barrington SF, Kingston JE et al. The impact of PET scanning on management of paediatric oncology patients. Eur J Nucl Med Mol Imaging 2005; 32: 23-30.

25. MAISEY MN. Cost-effectiveness of PET in patient management. En: Positron emission tomography. Basic science and clinical practice. Eds: Valk P, Bailey D, Townsend D, Maisey M. Editorial Springer, London, 2003; 795-804.

26. KalfF V, Hicks RJ, Macmanus MP, Binns DS, MckenZIE AF, Ware RE et aL. Clinical impact of (18)F fluorodeoxyglucose positron emission tomography in patients with non-small-cell lung cancer: a prospective study. J Clin Oncol 2001; 19: 111-8.

27. JUWEID ME, CHESON BD. Positron-emission tomography and assessment of cancer therapy. N Engl J Med 2006; 354: 496-507.

28. SCHOder H, Larson SM. Positron emission tomography for prostate, bladder, and renal cancer. Semin Nucl Med 2004; 34: 274-92.

29. Schoder H, Yeung HW. Positron emission imaging of head and neck cancer, including thyroid carcinoma. Semin Nucl Med 2004; 34: 180-97.

30. Kato K, Kubota T, Ikeda M, Tadokoro M, Abe S, NAKano S ET AL. Low Efficacy of 18F-FDG PET for Detection of Uveal Malignant Melanoma Compared with 123I-IMP SPECT. J Nucl Med 2006; 47: 404-9.

31. Kumar R, Zhuang H, Alavi A. PET in the management of urologic malignancies. Radiol Clin North Am 2004; 42: 1141-53, ix. 